\title{
DEVELOPMENT OF THE DIDEM MODEL: COMPARATIVE EVALUATION OF CALPUFF AND SPRAY DISPERSION MODELS
}

\author{
MARCO RAVINA, DEBORAH PANEPINTO \& MARIA CHIARA ZANETTI \\ Department of Engineering for Environment, Land and Infrastructures, Politecnico di Torino, Italy
}

\begin{abstract}
In the last years, research efforts have been addressed on the effects of single and multiple pollutants on human health, in particular in densely populated areas. Modelling tools, integrating atmospheric science with the latest evidence available from air pollution epidemiology and exposure science, represent a valuable support to health impact assessment. This article considers the latest developments of the DIATI Dispersion and Externalities Model (DIDEM). To extend DIDEM's scope of analysis, the integration with different pollutant dispersion models was recently implemented. Particularly, in this article, a comparative evaluation between CALPUFF (California Puff) Lagrangian puff model and SPRAY Lagrangian particle model is presented. To help reaching this objective, the case study of Turin's district heating system, presented in previous publications, was re-considered and deepened. CALPUFF and SPRAY models were compared on the same emission scenario. $\mathrm{NO}_{\mathrm{x}}$ and total PM concentrations resulting from the simulations were of the same magnitude, with some difference in the spatial distribution. Total health damage costs differed between $8.5 \%$ and $9.7 \%$, with lower values corresponding to SPRAY simulations. This difference mostly corresponds to the different spatial distribution of pollutant concentrations which, in turn, correspond to different exposure levels. The possibility of selecting different modelling tools extends the usability of DIDEM to a larger set of applications, including a wider scope of application and a larger range of users. The results provide important information in the view of the characterization of the overall uncertainty of the impact pathway approach methodology.
\end{abstract}

Keywords: air pollution, impact pathway, dispersion modelling, health, external costs, heating network.

\section{INTRODUCTION}

Air pollution represents a hazard to human health. In the last years, research has been focused on the effect of single and multiple pollutants on human health, in particular in densely populated areas. Multipollutant air quality management schemes have been proposed and developed to mitigate these risks [1,2].

At the local scale, the impacts of air pollution on human health may be estimated with the support of modelling tools, which integrate atmospheric science with the latest evidence available from air pollution epidemiology and exposure science. A great number of codes and tools have been designed for this purpose [3]. Each model was addressed to a particular scope of analysis. Thus, each one presents specific features in terms of methodological approach, technical structure, spatial and temporal scope and resolution and other aspects. The use of modelling tools brings significant advantages of consistency and comparability of the results. On the other hand, users must be aware of the technical and operational specifications of the tool with regard to the context of analysis.

Presently, one of the most recognized and used methodologies for health impact assessment and calculation of externalities is the impact pathway approach (IPA), whose concept was introduced by the ExternE project [4]. This method requires information about air pollution concentration levels, the relationship between concentrations and health outcomes and the characteristics of the populations exposed. 
Recently, a new integrated tool for the calculation of environmental impacts, human health effects and external costs associated to air pollution was presented [5]. This tool is referred as the DIDEM model (DIATI Dispersion and Externalities Model), where DIATI stands for Department of Engineering for Environment, Land and Infrastructures of Turin Polytechnic, Italy. The DIDEM model was designed to analyse and compare two (or more) operating scenarios through an integrated implementation of the IPA-based health impact assessment associated to a calculation of health damage costs. The main features of DIDEM are:

- The integration of advanced pollutant dispersion modelling with the calculation of health concentration-response functions (CRFs), implemented following the latest World Health Organization (WHO) recommendations [8,9];

- The implementation of different confidence levels on CRF data reported by WHO [8,9], resulting in a precise estimation of uncertainty associated to the calculation of health effects;

- The implementation of updated monetary values of health effects introduced by the EU's Clean Air Policy Package [10].

Taking into account DIDEM model structure and features (fine spatial resolution and limited geographic scope), it will be applied at the local scale (e.g. urban areas) to compare the compatibility of different energy scenarios in supporting local policy planning.

The first version of DIDEM model was presented in Ravina et al. [5]. Subsequently, DIDEM model structure was developed and updated with new modules and functionalities; these changes were reported in Ravina et al. [6]. Then, updated DIDEM model was tested on a real case study, represented by a comparative analysis on the district heating $(\mathrm{DH})$ network of Turin, a town located in north-western Italy.

The objective of these improvements in DIDEM model development is the extension of its applicability to a wider scope of analysis. However, its applicability must be evaluated and tested. For this reason, this article reports an advanced methodological analysis of the recent model developments depicted in [6]. As recognized by previous studies [7], air quality modelling represents one of the main sources of uncertainty in the IPA-integrated modelling process. Therefore, this analysis focuses on the use of different modelling software tools for the simulation of pollutant dispersion and the related effects on the complete HIA analysis. The software tools under consideration are CALPUFF (California Puff), a Lagrangian puff model, and SPRAY, a Lagrangian particle model. The contribution of the dispersion modelling step to the overall uncertainty of the proposed methodology is evaluated, taking into account Turin case study [5], which is now reconsidered and deepened.

\section{METHODOLOGY}

The DIATI-integrated DIDEM is based on the IPA and calculates the concentration of pollutants and the delta-external costs associated to the comparative analysis of emission scenarios. Comparative analysis is obtained by comparing the present situation to an alternative (previous or yet to be implemented) operating energy scenario.

The methodological and operating structure of DIDEM is described in detail in [5]. Following the IPA, this model links the simulation of pollutant dispersion $\left(\mathrm{NO}_{\mathrm{x}}, \mathrm{PM}_{2.5}\right.$ and $\left.\mathrm{PM}_{10}\right)$ to the concentration-exposure-response functions provided by latest WHO recommendations [8,9]. Subsequently, the model associates monetary values to the incremental incidence 


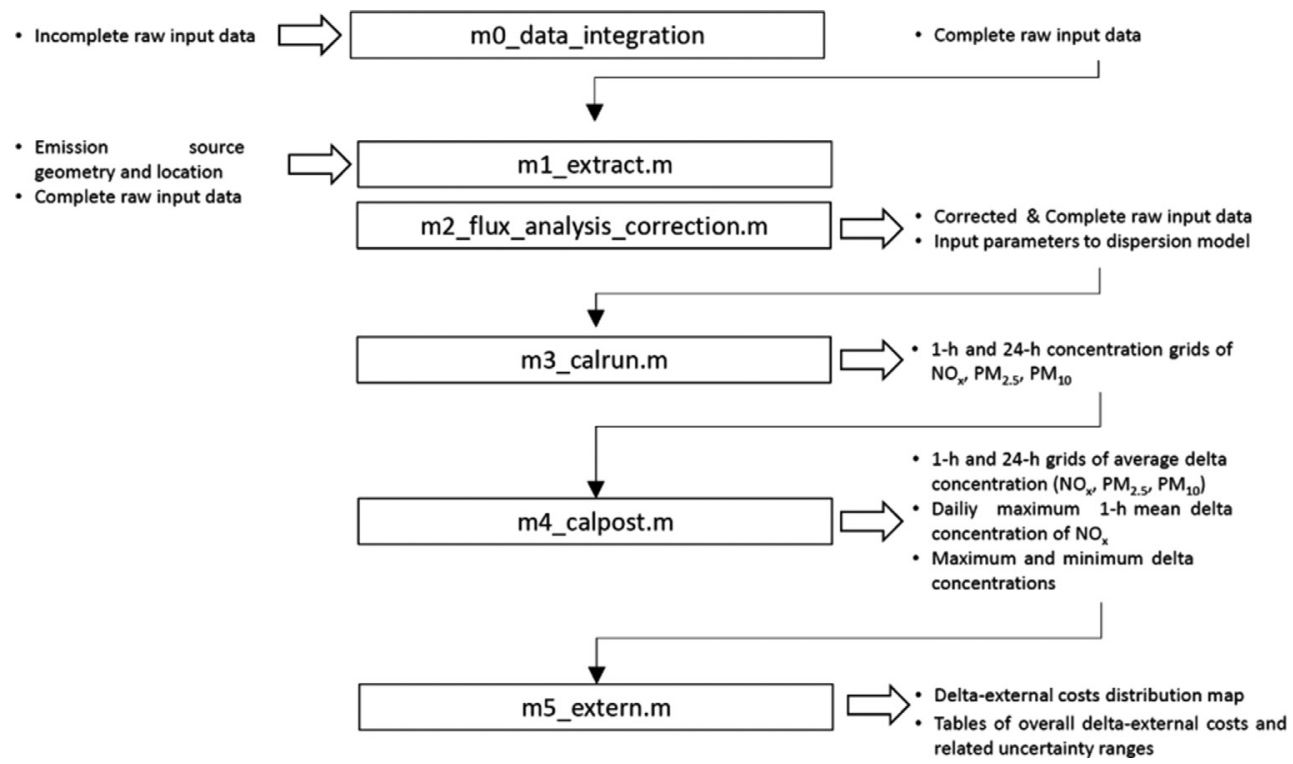

Figure 1: Modular structure of DIDEM model.

of health incomes. The code was developed in MATLAB ${ }^{\circledR}$ and is composed of the following six integrated modules (Fig. 1):

- Module 0 (m0_data_integration.m): integration of possible missing or incomplete data of emission sources;

- Module 1 (m1_extract.m): emission source data extraction and analysis;

- Module 2 (m2_flux_analysis_correction): emission source data analysis and correction;

- Module 3 (m3_calrun.m): dispersion model set-up and execution;

- Module 4 (m4_calpost.m): post-processing of dispersion model output: generation of delta-concentration maps, calculation of maximum and minimum delta concentrations and

- Module 5 (m5_extern.m): calculation of the variation of health incomes, delta-external costs and the related uncertainty range.

The operation of these modules is fully described in [5] and [6]. DIDEM model requires the following input data:

- Hourly emission flow of $\mathrm{NO}_{\mathrm{x}}, \mathrm{PM}_{2.5}$ and $\mathrm{PM}_{10}$ for each emission source (point and area sources are allowed);

- Physical parameters of the emission exhaust gas stream (temperature, velocity and flux);

- Geometric parameters of the emission sources (height, diameter and location);

- Population density grid over the modelling domain and

- Data of background rates of different health incomes in the area of study.

The following outputs are provided:

- Values of concentration differences for $\mathrm{NO}_{\mathrm{x}}, \mathrm{PM}_{2.5}$ and $\mathrm{PM}_{10}$ over the modelling domain grid cells (in ASCII format); 
- Tables of five maximum and minimum concentration differences, with their spatial positions in the domain grid and their times of occurrence;

- Spatial distribution of delta external costs, as values over the modelling domain grid cells and

- Tables reporting the total variation in health effects and external costs associated to the considered scenarios. The results reported herein are differentiated depending on the level of confidence of the input health effect/response pairs considered.

Currently, DIDEM is a living research project under development. The model was originally designed to run CALPUFF dispersion model. In DIDEM last version, new routines were implemented allowing the use of other dispersion models. Currently, two additional dispersion models may be used: Lagrangian particle model SPRAY [11] and the hybrid steadystate model AERMOD [12]. The main features of CALPUFF and SPRAY dispersion models, as well as the application of the extended DIDEM model on the Turin real case study, are reported in the following sections.

\subsection{Model description}

In its latest version, DIDEM model is structured to allow the user to select among three alternative dispersion models: CALPUFF, SPRAY and AERMOD.

CALPUFF is a multilayer, multispecies, non-steady-state Lagrangian puff dispersion model that simulates the effects of time- and space-varying meteorological conditions on pollution transport, transformation and removal [13]. The modelling system consists of three main components and a set of pre-processing and post-processing modules. The main components of the modelling system are CALMET (a diagnostic three-dimensional meteorological model), CALPUFF (an air quality dispersion model) and CALPOST (a post-processing package). The model includes algorithms for subgrid scale effects (such as terrain impingement), as well as longer range effects, such as pollutant removal due to wet scavenging and dry deposition, chemical transformation and visibility effects of particulate matter concentrations. CALPUFF simulates puffs of material emitted from modelled sources, reproducing dispersion and transformation processes along the way. The primary output files from CALPUFF contain either concentrations or deposition fluxes evaluated at selected receptor locations. CALPOST is used to process these files, identifying the highest and second highest 3-h average concentrations at each receptor, for example.

SPRAY $[11,14,15]$ is a three-dimensional Lagrangian particle dispersion model, which is able to take into account the spatial and temporal inhomogeneities of both mean flow and turbulence. Concentration fields generated by point, area or volume sources can be simulated by the model. The trajectory of the airborne pollutant is simulated through virtual particles: the mean motion is defined by the local wind and the dispersion is determined solving the Langevin stochastic differential equations for the velocity fluctuations, reproducing the statistical characteristics of the turbulent flow. Therefore, different portions of the emitted plumes can suffer different atmospheric conditions, allowing realistic representations of complex phenomena, such as low wind-speed conditions, strong temperature inversions, flow over topography, land use and terrain variability. SPRAY is a commercial model licensed by Arianet company [16]. This model can be driven by SWIFT diagnostic mass-consistent model, developed by Aria Technologies, Paris [17,18], and by the atmospheric prognostic model RAMS (adapted at ISAC-Torino [19,20]). 
AERMOD is a freeware hybrid stationary model representing an evolution of steady-state Gaussian models [12]. AERMOD was developed by the American Meteorological Society and US EPA, with the aim of realistically representing the dispersion in convective situations, while keeping the algorithmic simplicity of the Gaussian model.

These three codes represent subsequent steps of the evolution of pollutant dispersion modelling, so their results can be significantly different depending on the domain and its conditions. At first, all these models fit the scope of the DIDEM model and, for this reason, their integrated use was implemented. The selection of one model rather than another may depend on several factors: the scope and level of detail of the analysis, time constraints, economic and equipment constraints.

Currently, AERMOD is the most complete hybrid model, implementing all the theories of the dispersion in the convective PBL. In addition, it can also manage domains where there is no negligible orography. On the other hand, it has the major drawback of a steady-state model [22]. CALPUFF [13] is a Lagrangian puff model, and an extremely versatile tool to be applied at different scales of analysis (from local to regional scale) in unsteady conditions. It allows a detailed reconstruction of pollutants dispersion in a domain with complex orography or large cities. It also implements a number of schemes to calculate the chemical degradation of primary pollutants. On the contrary, even unsteady Lagrangian puff models as CALPUFF cannot reach a level of detail in concentration distribution comparable to particle models. In fact, they are not suitable when a detailed reconstruction of concentration distribution is required, since it is normally assumed the concentration inside a puff is normally distributed $[22,23]$. Lagrangian particle models (like SPRAY) show the ability of reproducing the close connection between micrometeorology and dispersion of pollutants. However, such an ability increases with increasing computational power, to generate a greater number of particles and use increasingly reduced time steps; also, particle model tuning is quite complex than puff model tuning. Lagrangian particle models are probably the only models currently able to realistically represent the dispersion in strongly convective conditions and close to the emission sources. The two main drawbacks of SPRAY are that it is a licensed model and it does not implement chemical and photochemical reactions.

\subsection{Model application (case study)}

In the past, DIDEM model was tested on a case study in the city of Turin, Italy $[5,6]$. This study focused on a comparative analysis of the operation of the DH network distributing thermal energy for household heating. The objective of the study was to compare the impacts on human health and environment presently generated by the cogeneration plants powering the DH network with an alternative scenario, where DH network is suppressed, and the operation of centralized autonomous, small-sized thermal installations was considered for household heating and sanitary hot water production.

Turin's DH network is currently powered by a system of three large cogeneration plants (Moncalieri 1, Moncalieri 2 and Torino Nord), four back-up units (Moncalieri, Torino Nord, BIT and Politecnico) and three pressurized steam storage systems (Torino Nord, Martinetto and Politecnico). The location of power plants and the DH network extension in the urban area of Turin is reported in Fig. 2. All conversion plants are fuelled by natural gas and were simulated as point sources. The height of these sources is $43 \mathrm{~m}$ (BIT plant), $50 \mathrm{~m}$ (Torino Nord and Politecnico plants) and $60 \mathrm{~m}$ (Moncalieri plants). Hourly data input of thermal energy production, $\mathrm{NO}_{\mathrm{x}}$ emission and total suspended particulate (TSP) emission for the year 


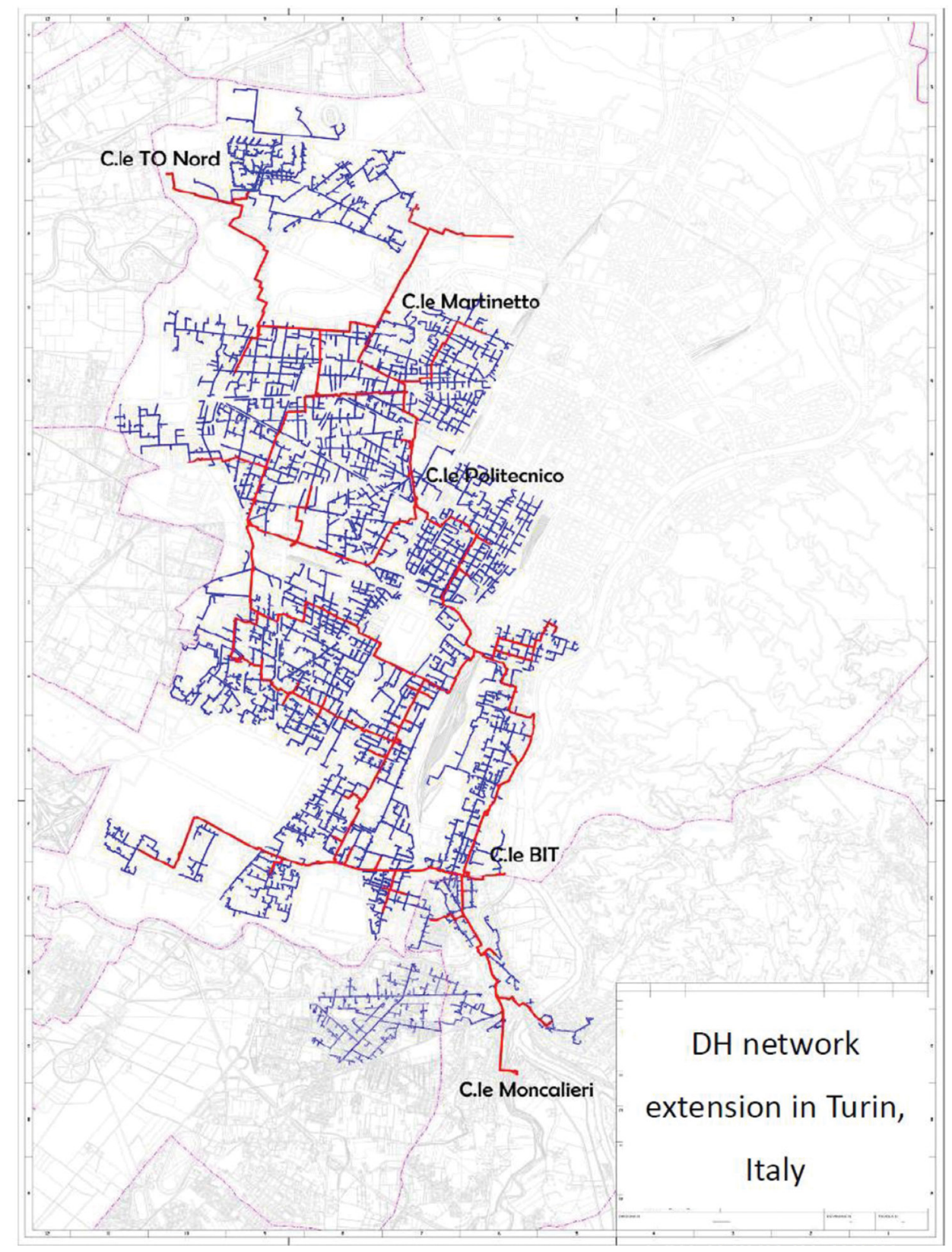

Figure 2: District heating network in Turin: location of the power plants and areas served.

2015 were provided by the plants' operator IREN ENERGIA [24]. Annual emission of pollutants is reported in Table 1.

Residential autonomous heating units were simulated as area sources, dividing the whole area served by the DH network in cells of $200 \mathrm{~m} \times 200 \mathrm{~m}$. A total of 74 sources were obtained. The pollutant emission flow of each emitting cell was calculated based on 
the average characteristics of the buildings herein included. Starting by building shape factors and period of construction, the annual thermal energy demand was calculated following the model proposed in the documentation of Turin metropolitan city energy planning [31]. Pollutant emissions from single buildings were calculated by multiplying thermal energy demand for specific emission factors. Specific emission factors of $80 \mathrm{~kg} / \mathrm{GWh}$ and $4.4 \mathrm{~kg} /$ GWh for $\mathrm{NO}_{\mathrm{x}}$ and TSP, respectively, were used, according to Piedmont's Regional Decree $\mathrm{n}$. 46-11968 [25]. The annual amount was then distributed on an hourly basis scaling it to the reference curve of a benchmark building subject to continuous monitoring of consumption. Emissions from the residential units were supposed to have a height of $25 \mathrm{~m}$. Annual emission of pollutants is reported in Table 1 .

$\mathrm{NO}_{\mathrm{x}}$ and $\mathrm{PM}_{2.5}$ emissions were studied for a 1-year period, considering a time resolution of $1 \mathrm{~h}$. Since these plants are fuelled by natural gas, total particulate is expected to be composed mainly of fine and ultra-fine components [32]. For this reason, $\mathrm{PM}_{2.5}, \mathrm{PM}_{10}$ and TSP emission flows were supposed to be equal. The meteorological input datasets collected in 2015 were used, since these were the latest available. The meteorological data had an hourly frequency. These data were obtained from the Regional Agency for Environmental Protection of the Piedmont Region (ARPA) [33] and included land use categories, altimetry, wind speed and direction (at ground and vertical observations), temperature (at ground and vertical observations), air pressure, air humidity, precipitation and solar radiation. Average wind distribution recorded at the Torino Alenia weather station is reported in Fig. 3. Weather and orographic

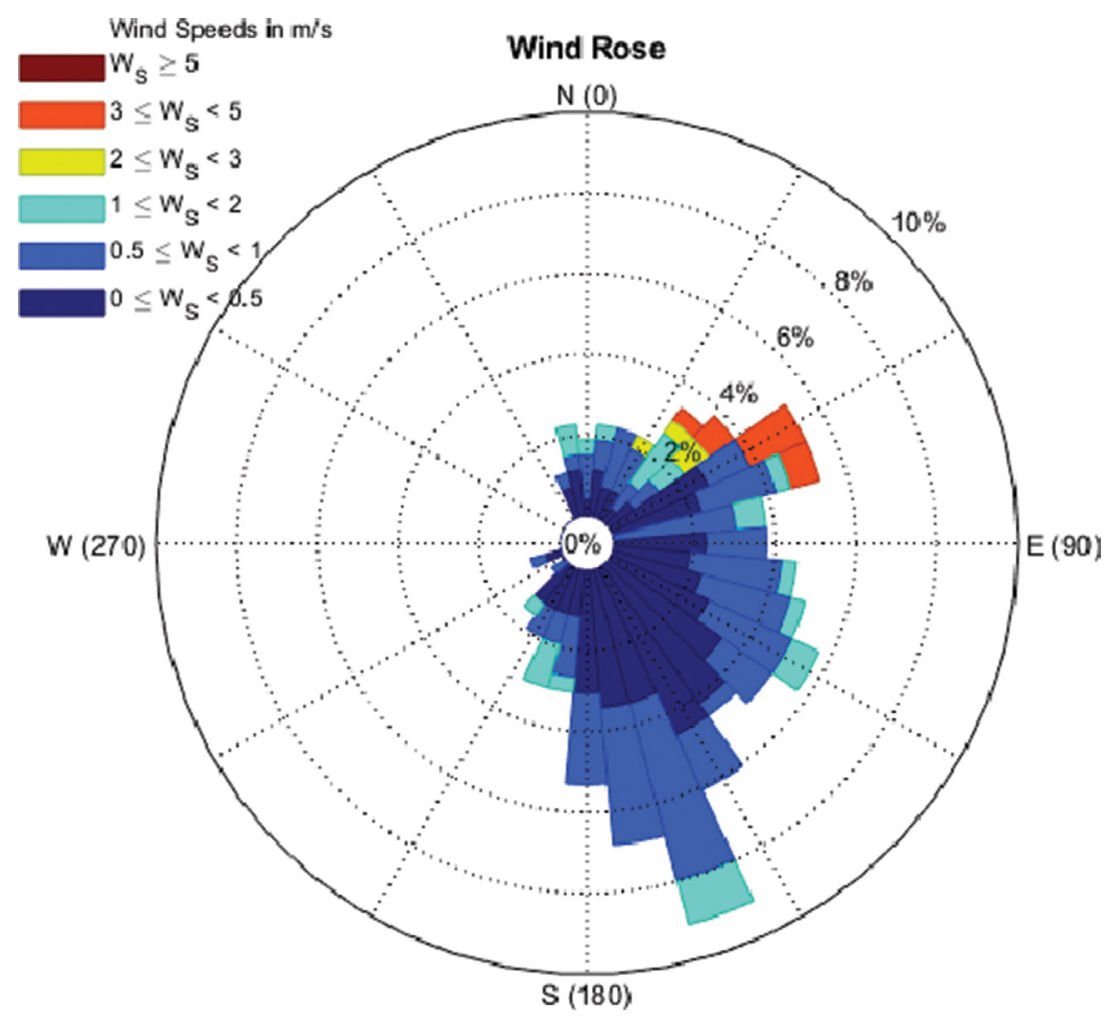

Figure 3: Average wind distribution at the Torino Alenia weather station in the year 2015. 
data had an initial spatial resolution of $1,000 \mathrm{~m}$ and covered a domain of $100 \mathrm{~km} \times 100 \mathrm{~km}$. The same grid represented also the initial dispersion modelling domain. After a first tuning phase, the domain extension was restricted to $40 \mathrm{~km} \times 40 \mathrm{~km}$ and the pre-processing modules were set to a resolution of $200 \mathrm{~m}$. The applied domain extension was considered adequate to consider the features of the area, which is characterized by two main orographic elements: the hills located next to the eastern side of Turin urban area and the Alps located approximately $30 \mathrm{~km}$ westwards.

In this study, the same scenarios were simulated with CALPUFF and SPRAY models, and the results were compared. The main difference in model settings is that a chemical transformation scheme, namely the MESOPUFF II scheme [30], was introduced in CALPUFF simulations. The transformation processes included in the MESOPUFF II mechanism are the conversion of sulphur dioxide to sulfate and of nitrogen oxides to nitrate aerosol. This was done to evaluate the possible contribution of secondary particulate formation to the overall concentration differences. Other options that were specific to one or another model were not considered. In particular, deposition and building downwash options were not considered. Both models were set to calculate horizontal and vertical dispersion from micrometeorological parameters. Plume rise calculation is based on Briggs formulation [34] in both models.

The output obtained from dispersion models, i.e. grids of average annual concentration of $\mathrm{NO}_{\mathrm{x}}$ and total PM, were introduced in a post-processing module (m4_calpost), generating 1-h and 24-h annual average concentrations of $\mathrm{NO}_{\mathrm{x}}, \mathrm{PM}_{2.5}$ and $\mathrm{PM}_{10}$, and daily maximum 1-h mean concentration of $\mathrm{NO}_{\mathrm{x}}$. These data were finally transferred to the last module (m5 extern) calculating health effects and costs.

Alternative scenarios were simulated separately and then compared. Final results were represented in terms of difference of concentrations, health effects and externalities.

\section{CASE STUDY RESULTS}

The complete energy and emission balance of the first stage of the study (referred to year 2015 ) is reported in Table 1 . Table 1 confirms, as already reported by previous studies [26,27], that the installation of a DH network powered by large cogeneration plants brings a reduction of primary energy consumption, as well as a lower emission of gaseous pollutants.

The comparison of the results obtained by separate running of CALPUFF and SPRAY dispersion models is reported in Figs. 4 to 7. Results of $\mathrm{NO}_{\mathrm{x}}$ and $\mathrm{PM}$ concentrations follow the same spatial distribution, although different in magnitude. The 1-h yearly average $\mathrm{NO}_{\mathrm{x}}$ concentration generated by the emission of the power plants powering the DH system is reported in Fig. 4. Results of CALPUFF and SPRAY simulations are of the same magnitude, with

Table 1: Energy and pollutants emission balance for the first stage of Turin case study.

\begin{tabular}{llllll}
\hline Variable & $\begin{array}{l}\text { Power plants } \\
\text { to DH network }\end{array}$ & \multicolumn{2}{l}{$\begin{array}{l}\text { Autonomous heating } \\
\text { (no DH network) }\end{array}$} & \multirow{2}{*}{ Difference } \\
\cline { 3 - 5 } & & Heat & Electricity & Total & \\
\hline $\begin{array}{l}\text { Primary energy con- } \\
\text { sumption (GWh/y) }\end{array}$ & 9,992 & 10,746 & 3,705 & 14,451 & $-4,459$ \\
NO $_{\mathrm{x}}$ emission (t/y) & 327.7 & $1,353.9$ & 296.4 & $1,650.3$ & $-1,322.6$ \\
TSP emission (t/y) & 16.3 & 75.2 & 16.3 & 91.5 & -75.2 \\
\hline
\end{tabular}




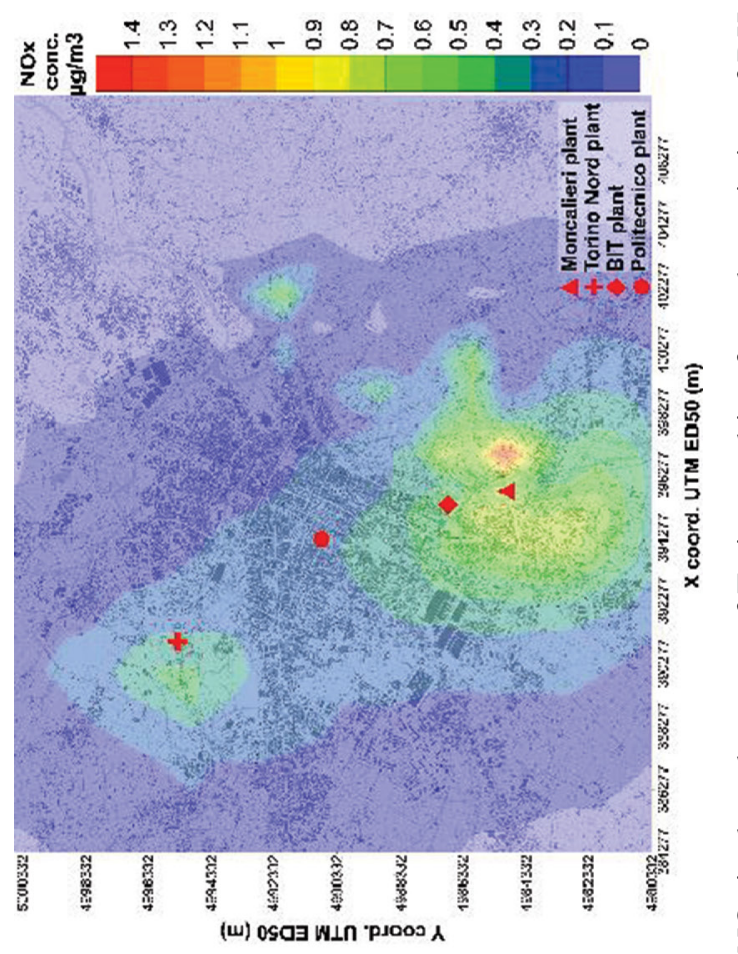

需

으

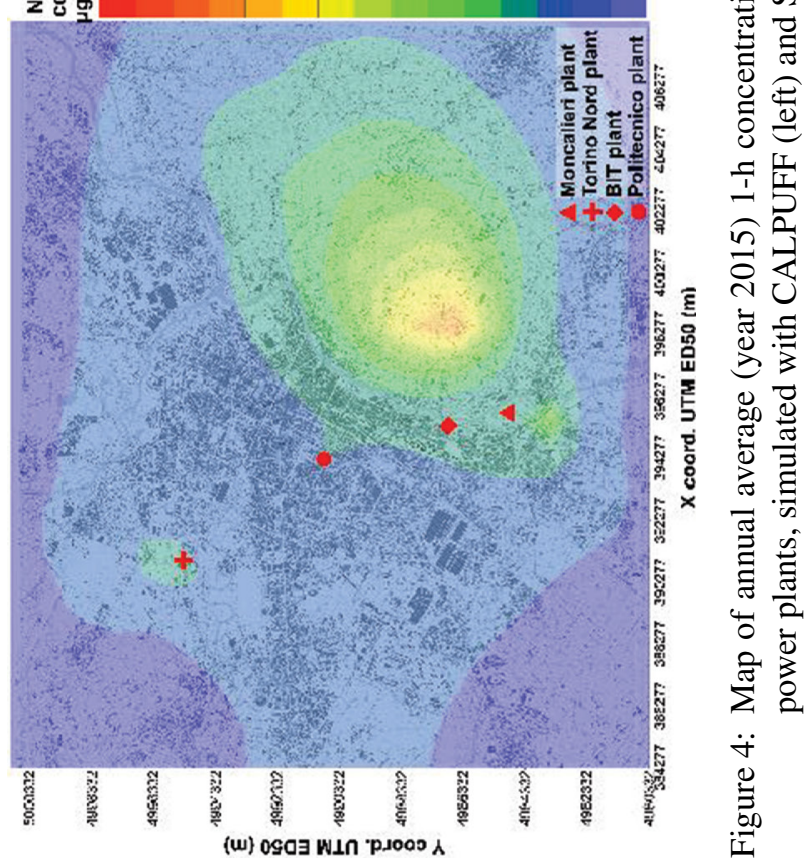




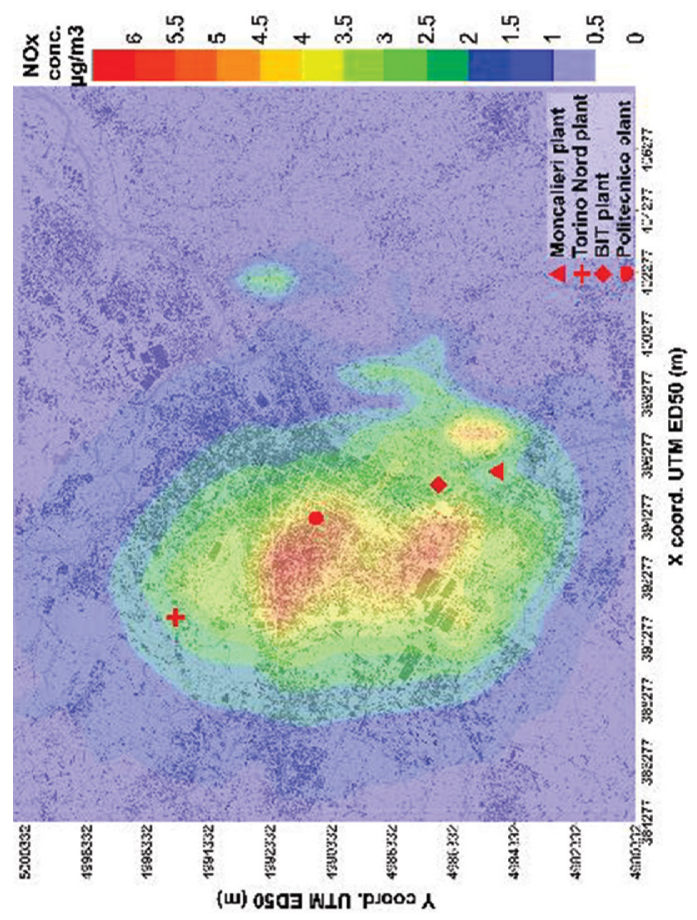

4

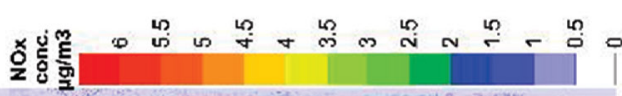
을

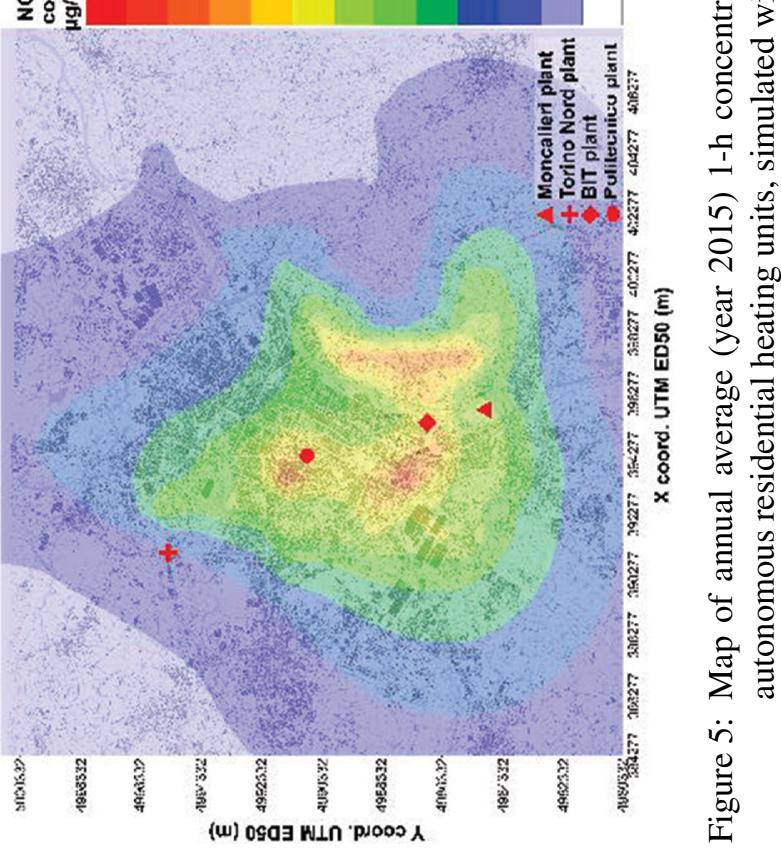




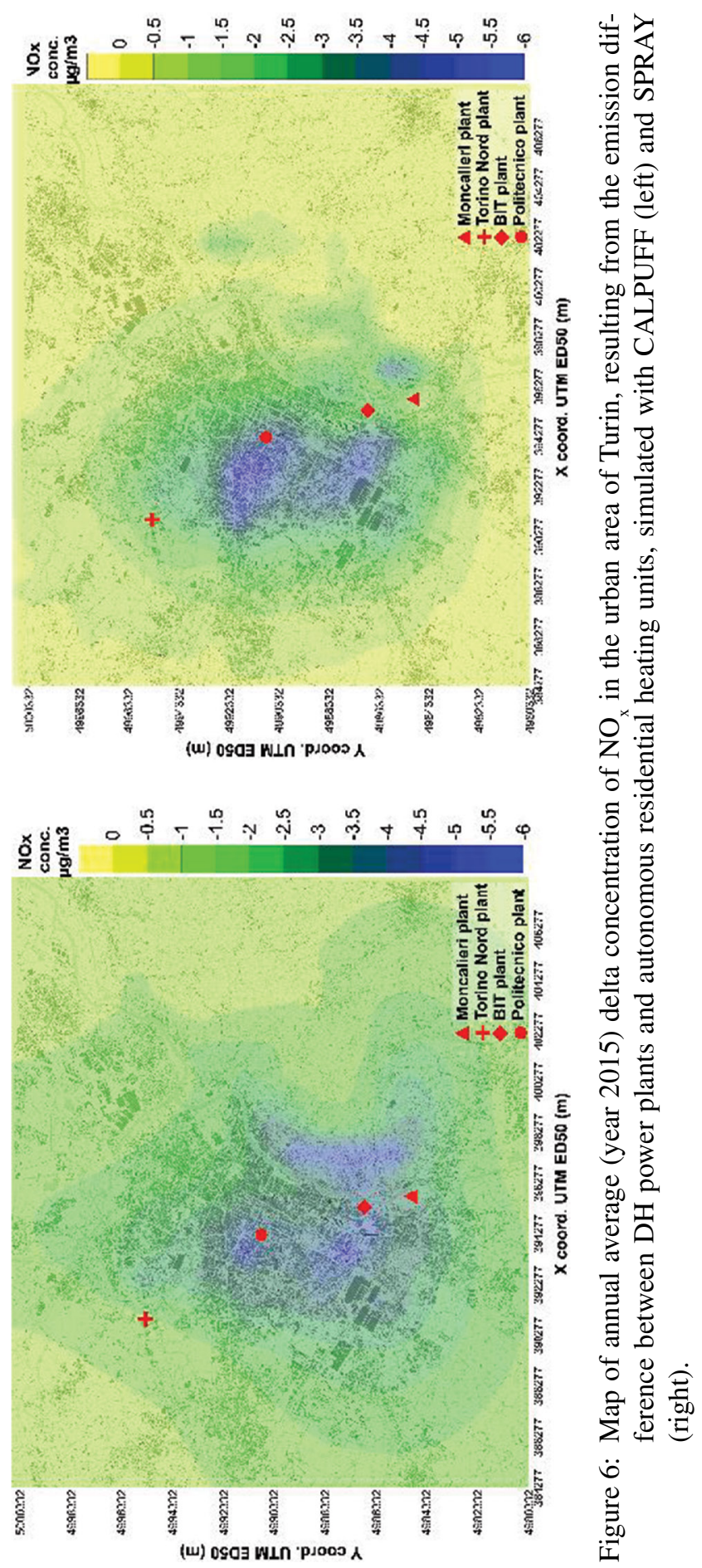




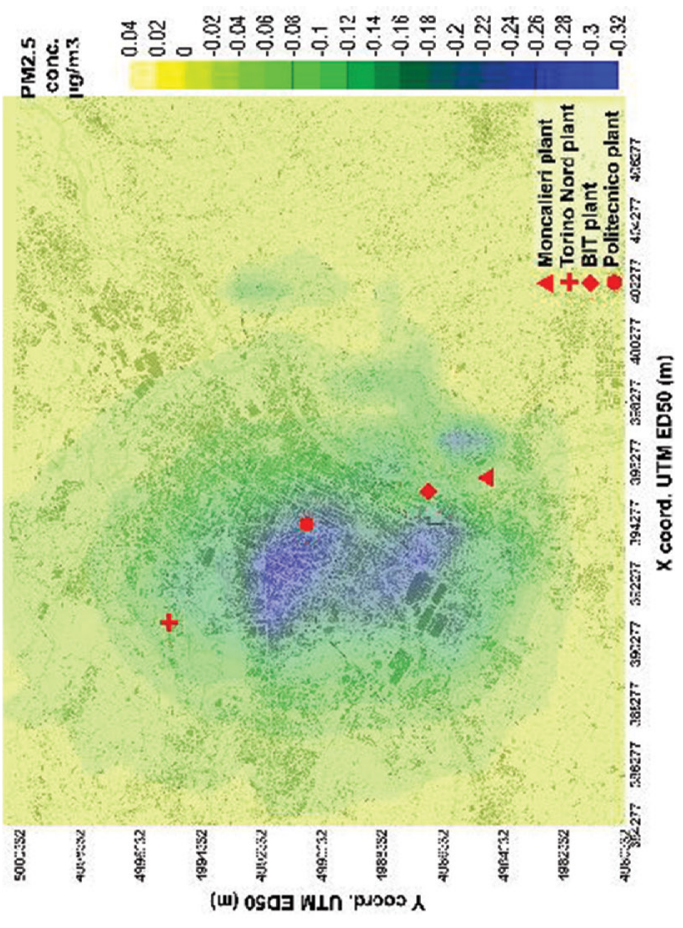

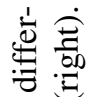

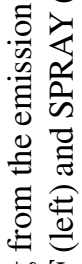

巨ิ

善 刍

胥

1

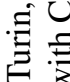

至

Ð

ㅊ.

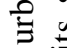

$\stackrel{\Xi}{\Xi}$

$\Xi \stackrel{0}{\Xi}$

(w) 0sa wLn pusos ᄉ

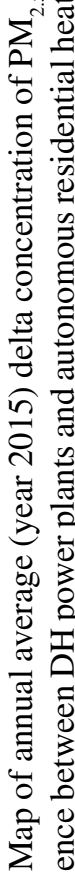

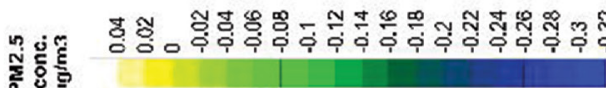

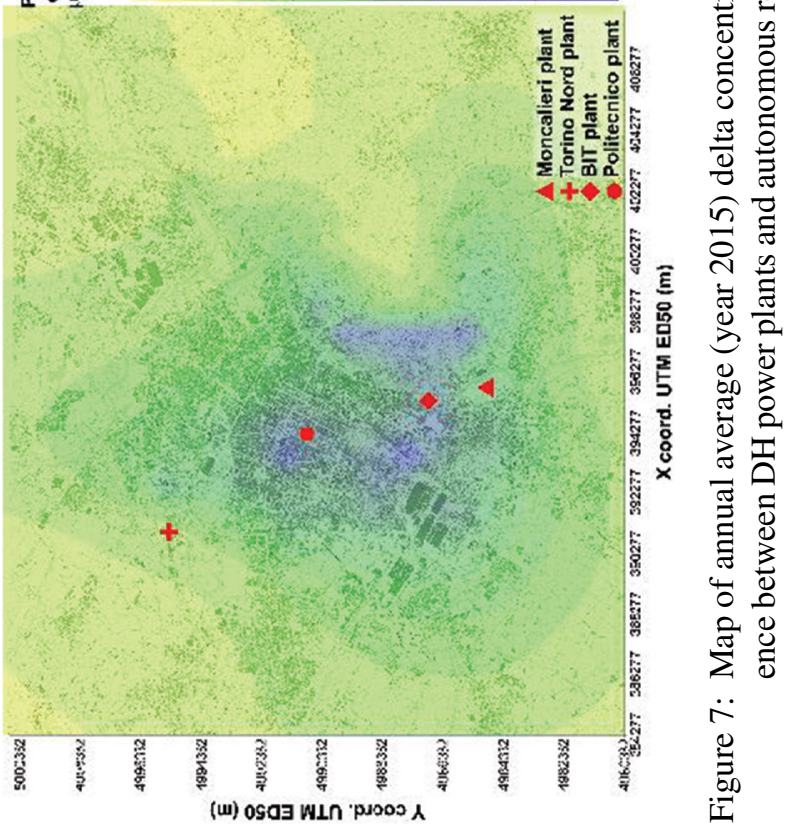


some difference in the spatial distribution of concentrations. The result of SPRAY appears with a more detailed spatial resolution, while CALPUFF generated uniform isolines. Similarly, the effect of the presence of the hilly areas located east of the city centre seems to be better reproduced by SPRAY. Also, SPRAY simulation results show higher average concentrations according to the two main power plants of the system (Torino Nord and Moncalieri). The 1-h yearly average $\mathrm{NO}_{x}$ concentration generated by the emission of the residential autonomous heating units is reported in Fig. 5. Also in this case, the results of CALPUFF and SPRAY simulations are of the same magnitude. The spatial distribution of concentrations appears similar. The $\mathrm{NO}_{\mathrm{x}}$ and $\mathrm{PM}_{2.5}$ concentrations maps representing the difference between the two scenarios (Figs. 6 and 7) confirm this trend. The maps reporting the delta-external health costs are reported in Fig. 8. The spatial distribution of delta-external health costs appears similar for the two cases, with higher cost reduction in areas with higher population density. Nevertheless, health cost reduction is generally lower in the case of SPRAY simulations. This trend is confirmed by Table 2, where the total health cost reduction is reported. Table 2 shows that the use of SPRAY dispersion model in the DIDEM-integrated simulation brings a lower estimation of health costs for the considered scenario than using CALPUFF model. Results reported in Table 2 are differentiated based on two groups of pollutant-outcome pairs, as reported by [8]:

- Group A (high confidence): pollutant-outcome pairs for which enough data are available to enable reliable quantification of effects and

- Group B (medium confidence): pollutant-outcome pairs for which there is more uncertainty about the precision of the data used for quantification of effects.

Delta-external costs show differences of $8.5 \%$ and $9.7 \%$ for high-confidence and mediumconfidence pollutant-outcome pairs, respectively.

\section{DISCUSSION}

The results reported in the extension of Turin case study confirm that the presence of the DH network in the urban area of Turin leads to significant advantages in terms of air quality and avoided impacts on human health. The alternative use of CALPUFF and SPRAY dispersion models showed to have an impact to the total health damage cost reduction. Simulation results differed between $8.5 \%$ and $9.7 \%$, with lower health cost estimations using SPRAY.

To discuss the reasons of such a discrepancy, the general equation for the calculation of external costs through the IPA should be recalled. Total external health costs are calculated as in [28],

$$
C_{i, r}=\sum_{r} \sum_{i}\left[\Delta c_{r} \times p_{r}\right] \times t \times s_{C R i} \times m_{i}
$$

where $C_{\mathrm{i}, \mathrm{r}}$ represents the damage costs related to health impact $i$ and to domain cell $r$, given in $€_{\text {base year }} ; \Delta c_{\mathrm{r}}$ is the concentration change of a given pollutant, referred to domain cell $r$, given in $\left[\mu \mathrm{g} / \mathrm{m}^{3}\right]$ (1-h, 24-h annual average or daily maximum 1-h mean, depending on the health impact $i$ considered); $p_{\mathrm{r}}$ is the number of exposed individuals [person]; $t$ is a factor to account for different assumptions on particle toxicity (in the present case study assumed equal to 1, i.e. all particles were assumed to have equal toxicity); $s_{\mathrm{CRi}}$ is the slope of the impact function of health impact $i$, given in $\left[(\right.$ additional cases $) /\left(\left(\mu \mathrm{g} / \mathrm{m}^{3}\right) \times\right.$ person $\times$ year $\left.)\right]$, 


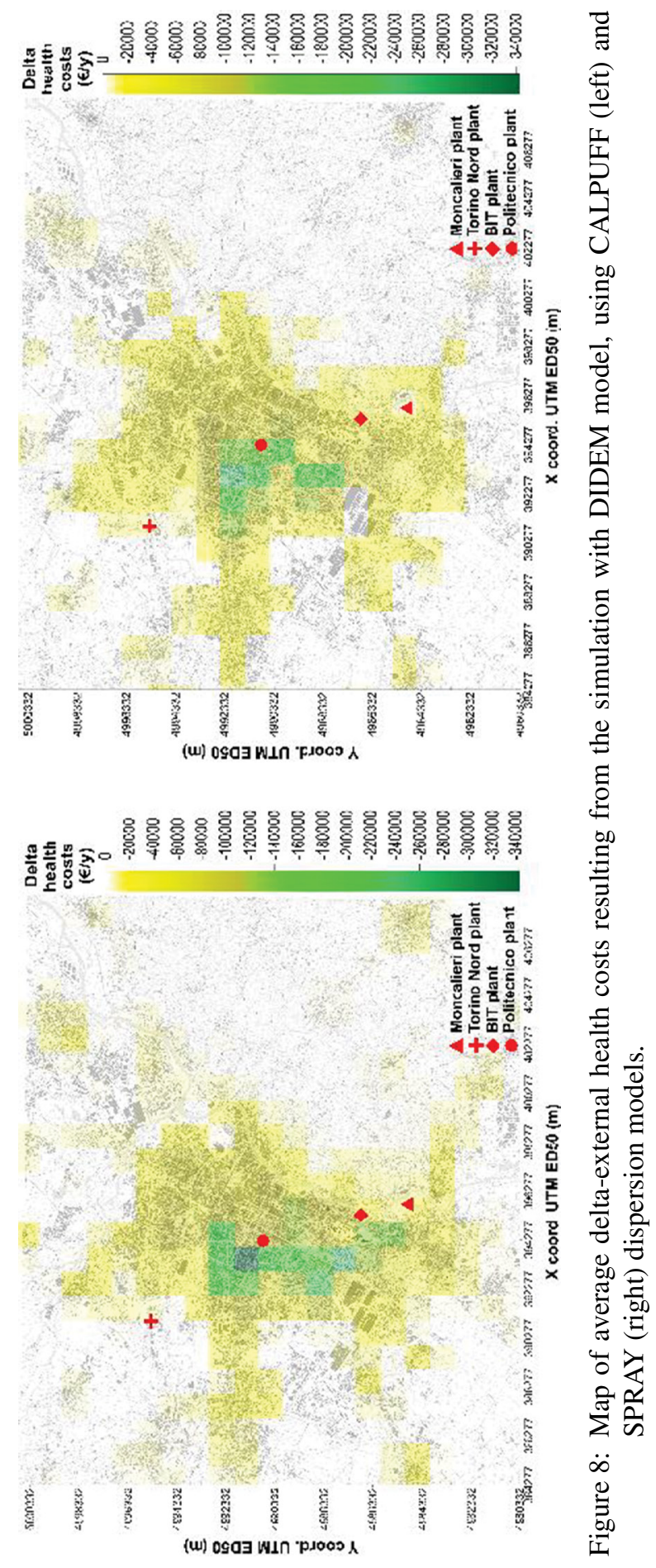


Table 2: Delta-external health costs for the case study resulting from simulation with DIDEM, using CALPUFF and SPRAY dispersion models.

\begin{tabular}{llll}
\hline $\begin{array}{l}\text { Dispersion } \\
\text { model }\end{array}$ & $\begin{array}{l}\text { Delta-external costs } \\
\text { (€/year, high-confidence } \\
\text { pollutant-outcome pairs, } \\
\text { Group A) }\end{array}$ & $\begin{array}{l}\text { Delta-external costs } \\
(€ / \text { year, medium-confidence } \\
\text { pollutant-outcome pairs, } \\
\text { Group A+B) }\end{array}$ & Difference \% \\
\hline CALPUFF & $-6,041,000$ & $-5,530,000$ & 8.5 \\
SPRAY & $-39,329,000$ & $-35,500,000$ & 9.7 \\
\hline
\end{tabular}

merging information on the risk increase and baseline rate of a given health impact $i$; and $m$ is the monetary value per case of health impact $i$, given in [ $€_{\text {base year }} /$ case].

In this specific case, the factors generating difference in the results are those related to concentrations $\left(\Delta c_{\mathrm{r}}\right.$ term) and exposure $\left(p_{\mathrm{r}}\right.$ term). A change of one of these terms means a change of the resulting health damage cost. The results of pollutant dispersion modelling, reported from Fig. 4 to Fig. 7, confirm that both CALPUFF and SPRAY model are, in principle, suitable for the scope and scale of the case study considered. The isolines generated by SPRAY result are more detailed and should better represent the disturbance of orographic elements on pollutant dispersion. Previous experiences reported in bibliography show that Lagrangian particle models are more realistic, both during stable and unstable atmospheric conditions [29]. With the same meteorological input, Lagrangian particle models have been observed to show a better agreement to measurements than puff models, especially, like in this case, when the plume impacts are sparse [35]. The advantage of CALPUFF simulations was that the formation of secondary particulate and $\mathrm{NO}_{\mathrm{x}}$ decay were also taken into account by implementing the Mesopuff II scheme [30]. However, considering the temporal and spatial scale of the study, it can be concluded that this option had a minor effect on the results.

Observing delta-concentration maps reported from Fig. 4 to Fig. 7, it seems that part of the difference in model simulations might be due to the complexity of the terrain, which presents high slopes in correspondence of the hilly areas located east of Turin city centre. In fact, CALPUFF model apparently tends to accumulate pollutants in correspondence of marked slope changes. This effect might be due to the parameterization of the interaction between the pollutant plumes and the terrain. This aspect should be evaluated by future research studies.

The analysis of the average concentration maps reported from Fig. 4 to Fig. 7 does not completely explain the difference in the results using CALPUFF and SPRAY, because population exposure in not contemplated therein. Different spatial distribution of concentrations corresponds to different exposure levels of population and, in turn, to different change in health damage costs. This aspect explains the main difference in the results, i.e. delta concentrations of CALPUFF simulations were higher where the exposition (number of residents) was also higher. This is partially confirmed by Fig. 8, showing that health damage cost reduction in the urban centre of Turin is less pronounced in the case of SPRAY simulations.

The results reported in this study provide important information on the overall uncertainty related to the integrated modelling chain. The impact pathway methodology combines information from different sources, including pollutant dispersion modelling, estimation of pollutant exposure and epidemiologic assumptions. Each of these information sources carries 
with it some degree of uncertainty that influences the precision and confidence in the health impact results [3]. The uncertainty related to air modelling has been showed to contribute in a significant amount to the overall error [28]. Characterizing the total uncertainty in the final health risk and impact results is challenging. An intercomparative analysis conducted on the air quality modelling step, like that reported in this study, can provide useful information on these aspects.

\section{CONCLUSION}

DIDEM model was engineered at the Department of Engineering for Environment, Land and Infrastructures of Turin Polytechnic, Italy, with the aim of integrating pollutant dispersion modelling $\left(\mathrm{NO}_{\mathrm{x}}\right.$ and $\left.\mathrm{PM}\right)$ with the calculation of health effects and costs. This article presented a deepening of the analysis of the structure of DIDEM model last version and its new capabilities. It includes the alternative use of SPRAY and AERMOD dispersion models, in addition to CALPUFF. A comparative evaluation of DIDEM simulations with CALPUFF and SPRAY model was done, using Turin's DH network as test case.

As evaluation results are quite similar, they confirm that both dispersion models, SPRAY and CALPUFF, can be used in DIDEM. Therefore, the possibility of selecting different modelling tools extends the usability of DIDEM to a larger set of applications, including a wider scope of application and a larger range of users that are more confident with any of those dispersion models.

The intercomparative analysis on air quality modelling reported in this study provided important information on the contribution of the air modelling step overall uncertainty of the IPA methodology. Provided that environmental externalities could represent an efficient support to environmental and energy planning, further research efforts should be directed towards this direction, as the decision-making process of energy and environmental planning has to be supported by efficient, integrated and socially oriented modelling tools.

\section{REFERENCES}

[1] Wesson, K., Fann, N., Morris, M., Fox, T., Hubbell, B. A multipollutant risk-based approach to air quality management: Case study for Detroit. Atmospheric Pollution Research, 1, pp. 296-304, 2010.

[2] Fann, N., Wesson, K., Hubbell, B. Characterizing the confluence of air pollution risks in the United States. Air Quality Atmosphere, and Health, 2015. DOI: 1007/s11869-0150340-9.

[3] Anenberg, S.C., Belova, A., Bramdt, J., Fann, N., Greco, S., Guttikunda, S., Heroux, M.E., Hurley, F., Krzyzanowski, M., Medina, S., Miller, B., Pandey, K., Roos, J., Van Dingenen, R. Survey of ambient air pollution health risk assessment tools. Risk Analysis, 36(9), pp. 1718-1736, 2016. DOI: 10.1111/risa.12540.

[4] European Commission. Externalities of Energy - Vol. 2: Methodology - method for estimation of physical impacts and monetary valuation for priority impact pathways. European Commission DG XII "Science, Research and Development", JOULE: Luxembourg, 1995

[5] Ravina, M., Panepinto, D., Zanetti, M.C. DIDEM - An integrated model for comparative health damage costs calculation of air pollution. Atmospheric Environment, 173, pp. 81-95, 2018a. DOI: https://doi.org/10.1016/j.atmosenv.2017.11.010.

[6] Ravina, M., Panepinto, D., Zanetti, M.C. A dispersion and externalities model supporting energy systems planning: development and case study. WIT Transactions on Ecology and the Environment, Vol. 230, WIT Press, 2018b. ISSN 1743-3541 
[7] Boldo, E., Linares, C., Aragones, N., Lumbreras, J., Borge, R., de la Paz, D., PerezGomez, B., Fernandez-Navarro, P., Garcia-Perez, J., Pollan, M., Ramis, R., Moreno, T., Karanasiou, A., Lopez-Abente, G. Air quality modeling and mortality impact of fine particulate matter reduction policies in Spain. Environmental Research, 128, pp. 15-26, 2014. DOI:10.1016/j.envres.2013.10.009.

[8] WHO. Health Risks of Air Pollution in Europe - HRAPIE Project. Recommendations for concentration-response functions for cost-benefit analysis of particulate matter, ozone and nitrogen dioxide, World Health Organization, Regional Office for Europe: Copenhagen, Denmark, p. 54, 2013 a.

[9] WHO. Review of evidence on health aspects of air pollution - REVIHAAP Project. Technical report, The WHO European Centre for Environment and Health: Bonn, Germany, p. 302, 2013b.

[10] Holland, M. Cost-Benefit Analysis of Final Policy Scenarios for the EU Clean Air Package - Version 2, Corresponding to IIASA TSAP Report 11, Version 2a. EMRC, 2014.

[11] Tinarelli, G., Anfossi, D., Bider, M., Ferrero, E. \& Trini Castelli, S. A new high performance version of the Lagrangian particle dispersion model SPRAY, some case studies. Air Pollution Modelling and its Application XIII, Vol. 23, eds. Gryning S.E. \& E. Batchvarova, Plenum Press: New York, pp. 499-506, 2000. ISBN: 0-306-46188-9

[12] U.S. EPA. AERMOD implementation guide. U.S. Environmental Protection Agency, Office of Air Quality Planning and Standards, Air Quality Assessment Division, AERMOD Implementation Workgroup, Research Triangle Park: North Carolina, 2018.

[13] U.S. Environmental Protection Agency (US EPA), CALPUFF modeling system user's manual, version 6, 2011.

[14] Tinarelli, G., Anfossi, D., Brusasca, G., Ferrero, E., Giostra, U., Morselli, M.G., Moussafir, J., Tampieri, F. \& Trombetti, F., Lagrangian particle simulation of tracer dispersion in the lee of a schematic two-dimensional hill. Journal of Applied Meteorology, 33(N. 6), pp. 744-756, 1994.

[15] Tinarelli, G., Anfossi, D., Bider, M., Ferrero, E., Trini Castelli, S., A new high performance version of the Lagrangian particle dispersion model SPRAY, some case studies. Air Pollution Modelling and its Application XIII, Vol. , 23, eds. Gryning S.E. \& E. Batchvarova, Plenum Press: New York, pp. 499-506, 2000. ISBN: 0-306-46188-9.

[16] Arianet company http://www.aria-net.it/ (accessed September 20).

[17] Aria Technologies http://www.aria.fr/ (accessed September 20).

[18] Tinarelli, G., Brusasca, G., Oldrini, O., Anfossi, A., Trini Castelli, S. \& Moussafir, J. Micro-Swift-Spray (MSS) a new modeling system for the simulation of dispersion at microscale. General description and validation. Air Pollution Modeling and its Applications XVII, eds., C. Borrego \& A.N. 10 Norman, Springer, pp. 449-458, 2007.

[19] ISAC Istituto di Scienze dell'Atmosfera e del Clima http://www.isac.cnr.it/it/content/ torino (accessed September 20).

[20] Trini Castelli, S., Ferrero, E., Anfossi, D. \& Ohba, R. Turbulence closure models and their application in RAMS. Environmental Fluid Mechanics 5(Number 1-2), pp. 169192, 2005.

[21] Nieuwstadt, F.T.M., van Dop H. Turbulence and Air Pollution Modeling - Reidel Publishing Company, 1982.

[22] Venkatram, A., Wyngaard, J.C. Lectures on Air Pollution Modeling - American Meteorological Society, 1988. 
[23] Seinfeld, J.H. \& Pandis, S.N. 2006. Atmospheric Chemistry and Physics 2nd ed, J. Wiley \& Sons

[24] Iren Energia company website. http://www.irenenergia.it/. (accessed September 20).

[25] Piedmont Region. Decree of the Regional Council of 4 August 2009, no. 46-11968. Update of the Regional Plan for the Rehabilitation and Protection of Air Quality - Draft plan for environmental heating and conditioning and implementing provisions on energy performance in construction pursuant to Article 21, paragraph 1, letters a) b) q) of Regional Law 28 May 2007, no. 13. In Italian, 2009.

[26] Ravina, M., Panepinto, D., Zanetti, M.C., Genon, G. 2017. Environmental analysis of a potential district heating network powered by a large-scale cogeneration plant. Environmental Science and Pollution Research, 24, pp. 13424-13436, 2009, DOI: 10.1007/ s11356-017-8863-2.

[27] Ravina, M., Panepinto, D. \& Zanetti, M.C., District heating system: evaluation of environmental and economic aspects. International Journal of Environmental Impacts, 1(4), pp. 420-432, 2018. DOI: 10.2495/EI-V1-N4-420-432.

[28] van der Kamp, J. \& Bachmann, T.M., Health-related external cost assessment in Europe: methodological developments from ExternE to the 2013 clean air policy package. Environmental Science \& Technology, 49, pp. 2929-2938, 2015. DOI: 10.1021/ es5054607.

[29] Rodean, H.C., Stochastic Lagrangian Models of Turbulent Diffusion, American Meteorological Society. 1996.

[30] Scire, J.S., Lurmann, F.W., Bass, A. \& Hanna, S.R., User's guide to the MESOPUFF II model and related processor programs. EPA-600/8-84-013. U.S., Environmental Protection Agency, Research Triangle Park. 1984.

[31] Fracastoro, G.V. \& Serraino, M., A methodology for assessing the energy performance of large scale building stocks and possible applications. Energy and Buildings, 43, pp. 844-852, 2011. DOI: https://doi.org/10.1016/j.enbuild.2010.12.004.

[32] Chang, M.C.O., Chow, J.C., Watson, J.G., Hopke, P.K., Seung-Muk, Y. \& England, G.C., Measurement of ultrafine particle size distributions from coal-, oil-, and gas-fired stationary combustion sources, Journal of the Air \& Waste Management Association, 54(12), pp. 1494-1505, 2004. DOI: 10.1080/10473289.2004.10471010.

[33] Piedmont's Regional Agency for the Environmental Protection. http://www.arpa.piemonte.it/ (last accessed 2019-05-10)

[34] Briggs, G.A., Plume rise predictions. Lectures on Air Pollution and Environmental Impact Analyses. ed. D. Haugen, American Meteorological Society: Boston, MA, pp. 59-111, 1982.

[35] Souto, M.J., Souto, J.A., Pérez-Muñuzuri, V., Casares, J.J. \& Bermudez, J.L., A comparison of operational Lagrangian particle and adaptive puff models for plume dispersion forecasting. Atmospheric Environment, 35, pp. 2349-2360. 2001. 